\title{
Rancang Bangun Sistem Informasi Konferensi Nasional Aptikom Provinsi Kalimantan Barat Berbasis Web
}

\author{
Leonardus Fernando $^{\# 1}$, Novi Safriadi ${ }^{* 2}$, Rudy Dwi Nyoto ${ }^{\# 3}$ \\ "Program Studi Informatika Universitas Tanjungpura \\ Jl. Profesor Dokter H. Hadari Nawawi, Bansir Laut, Pontianak Tenggara, Kota Pontianak, Kalimantan Barat 78115 \\ ${ }^{1}$ leociffer@gmail.com \\ ${ }^{2}$ safriadieinformatics.untan.ac.id \\ ${ }^{3}$ rudydneinformatika.untan.ac.id
}

\begin{abstract}
Abstrak- Asosiasi Pendidikan Tinggi Informatika dan Komputer Provinsi Kalimantan Barat (Aptikom Kalbar) adalah asosiasi yang didirikan oleh dan beranggotakan seluruh program studi informatika dan komputer di wilayah provinsi Kalimantan Barat. Aptikom Kalbar merupakan salah satu organisasi yang mengadakan konferensi nasional setiap tahunnya. Konferensi merupakan ajang pertemuan dan berbagi antara pemakalah yang mengirimkan makalah. Ragamnya peserta atau pemakalah yang mengikuti konferensi nasional menyebabkan diperlukannya suatu media atau sistem yang mengelola proses pendaftaran hingga pembayaran dalam konferensi. Tujuan dari penelitian ini adalah untuk menghasilkan sebuah sistem yang mampu mengatasi semua proses mulai dari pendaftaran peserta, unggah makalah, penilaian makalah sampai pembayaran. Sistem informasi konferensi dirancang untuk digunakan oleh beberapa pengguna, seperti peserta, reviewer, dan admin. Pengujian sistem dilakukan dengan pengujian black box. Jenis dari pengujian black box yang digunakan dalam pengujian sistem ini adalah robustness testing. Hasil pengujian Black Box Robustness telah berjalan dengan fungsinya sesuai kebutuhan fungsional yang telah didefinisikan. Hasil akhir pada penelitian ini menghasilkan sebuah sistem informasi yang mampu mengatasi masalah pengelolaan konferensi. Demikian sistem informasi konferensi nasional Aptikom Kalbar berbasis web layak untuk diimplementasikan.
\end{abstract}

Kata kunci - seminar, konferensi, sistem informasi, Aptikom Kalbar, teknologi berbasis web

\section{Pendahuluan}

Asosiasi Pendidikan Tinggi Informatika dan Komputer Provinsi Kalimantan Barat (APTIKOM Kalbar) adalah asosiasi yang didirikan oleh dan beranggotakan seluruh program studi informatika dan komputer di wilayah provinsi Kalimantan Barat. APTIKOM sebagai sebuah asosiasi yang merupakan kerjasama antara perguruan tinggi di bidang IT diharapkan dapat menjadi wadah untuk dapat meningkatkan kerjasama baik antar perguruan tinggi, maupun antar perguruan tinggi dengan pemerintah dan pelaku usaha. [1]

Seminar dan konferensi merupakan salah satu kegiatan yang sering dilakukan oleh suatu institut atau lembaga pendidikan. Pertemuan atau persidangan dalam seminar biasanya menampilkan satu atau beberapa pembicaraan dengan makalah atau kertas kerja masing-masing. Seminar biasanya diadakan untuk membahas suatu masalah secara ilmiah, yang berpartisipasi pun orang yang ahli dalam bidangnya. [2]

Adapun salah satu kegiatan yang akan diselenggarakan oleh APTIKOM Provinsi Kalimantan Barat ialah melaksanakan konferensi nasional di bidang informatika dan komputer. Konferensi ini akan diikuti oleh dosen maupun mahasiswa dari berbagai perguruan tinggi di Indonesia. Dalam kegiatan ini pihak peserta konferensi perlu mendaftarkan diri kepada penyelenggara konferensi, yang dapat dilakukan melalui email, maupun aplikasi sistem informasi. Calon peserta terdiri dari peserta pemakalah dan peserta non pemakalah. Bagi peserta pemakalah wajib mengirimkan makalah yang akan diikutsertakan pada konferensi tersebut. Selain itu, mekanisme selanjutnya setelah pendaftaran adalah peserta melakukan pembayaran biaya pendaftaran. Pendaftaran dan pembayaran ini kemudian dikonfirmasi oleh pihak penyelenggara. Jika komunikasi terkait pengiriman atau submit paper dan proses lainnya dilakukan melalui email maka hal ini dirasakan kurang efisien karena akan terjadi penumpukan pada email.

Terkait dengan hal itu, maka diperlukan sistem yang dapat mengakomodir registrasi peserta, seperti pendaftaran calon peserta, unggah makalah, konfirmasi pembayaran dan kehadiran bagi peserta, menerima dan review makalah oleh reviewer, unggah hasil review, serta penetapan peserta konferensi. Dari permasalahan tersebut, diusulkan sebuah 
sistem informasi konferensi nasional, untuk membantu APTIKOM Provinsi Kalimantan Barat dalam menyelenggarakan kegiatan konferensi nasional.

\section{LANDASAN TEORI}

\section{A. Definisi Konferensi}

Konferensi menurut Kamus Besar Bahasa Indonesia adalah rapat atau pertemuan untuk berunding atau bertukar pendapat mengenai suatu masalah yg dihadapi bersama. Seminar berarti pertemuan atau persidangan untuk membahas suatu masalah di bawah pimpinan ahli (guru besar, pakar, dsb).[3]

\section{B. Sistem Informasi}

Sistem adalah suatu integrasi bagian sistem informasi yang semuanya bekerja menuju suatu tujuan. Sistem terdiri dari tiga elemen utama yaitu input, pengolahan data dan output. Sistem juga dapat dibagi menjadi beberapa sistem ataupun sub sistem, yang masing-masing bagian mempunyai bagian umum seperti perangkat lunak, perangkat keras, manusia, basis data, prosedur dan dokumentasi. [4]

Informasi dapat didefenisikan sebagai hasil dari pengolahan data dalam suatu bentuk yang lebih berguna dan lebih berarti bagi penerimanya yang menggambarkan suatu kejadiankejadian (event) yang nyata (fact) yang digunakan untuk pengambilan keputusan. [5]

Sistem informasi terdiri dari semua komponen yang bekerja sama untuk mengolah data dan prosedur informasi. Komponen sistem informasi terdiri dari unsur-unsur seperti masukan (input), pengolahan (processing), keluaran (output) serta umpan balik (feedback).[6]

\section{Asosiasi Pendidikan Tinggi Informatika dan Komputer (APTIKOM)}

Asosiasi Pendidikan Tinggi Informatika dan Komputer Provinsi Kalimantan Barat (APTIKOM Kalbar) adalah asosiasi yang didirikan oleh dan beranggotakan seluruh program studi informatika dan komputer di Wilayah Provinsi Kalimantan Barat. APTIKOM sebagai sebuah asosiasi yang merupakan kerjasama antara perguruan tinggi di bidang IT diharapkan dapat menjadi wadah untuk dapat meningkatkan kerjasama baik antar perguruan tinggi, maupun antar perguruan tinggi dengan pemerintah dan pelaku usaha.[1]

\section{Data Flow Diagram}

Data flow diagram (DFD) adalah suatu diagram yang menggunakan notasi - notasi untuk menggambarkan arus data dari sistem, yang penggunaannya sangat membantu dalam memahami sistem secara logika, terstruktur, dan jelas. [7]

\section{E. Pengujian Black Box}

Black box testing berfokus pada persyaratan fungsional perangkat lunak yang memungkinkan engineers untuk memperoleh serangkaian kondisi input yang sepenuhnya akan melaksanakan persyaratan fungsional untuk sebuah program.[8]

\section{Penelitian DAN PeRANCANGAN Sistem}

\section{A. Analisis Sistem yang Sedang Berjalan}

Adapun sistem yang sedang berjalan pada pengolahan data konferensi Aptikom Kalbar masih belum memiliki sistem informasi khusus untuk menangani permasalahan dalam konferensi, seperti dimana data penerimaan makalah, proses review dan pemilihan reviewer makalah, konfirmasi bukti pembayaran dan pengiriman makalah camera ready yang dikelola menggunakan email yang mana akan terjadi penumpukan data. Mengingat cukup banyaknya data dan tidak tersimpan secara terstruktur, sehingga terlihat bahwa sistem yang sedang berjalan masih memiliki beberapa kelemahan.

\section{B. Sistem yang Akan Dibangun}

Berdasarkan analisis sistem yang sedang berjalan maka diperlukan sistem informasi yang mendukung kegiatan pengolahan data konferensi Aptikom Kalbar yang meliputi pengolahan data seminar, data makalah, data peserta pemakalah dan nonpemakalah, data reviewer, dan data pembayaran. Sistem ini dibangun agar kegiatan pengolahan data dan informasi dapat tersimpan secara terpusat, terstruktur dan penyampaian informasi dapat dilakukan dengan cepat.

1. Admin APTIKOM Provinsi Kalimantan Barat

Pengguna yang mempunyai hak penuh dalam mengakses sistem ini, khususnya halaman administrator sehingga diperlukan login terlebih dahulu sebelum mendapatkan fasilitas-fasilitas administrator.

Beberapa hal penting yang dapat dilakukan:

- memanajemen akun admin itu sendiri dan akun user lainnya,

- memanajemen konten pada halaman website,

- menambahkan akun reviewer,

- menentukan makalah diterima atau tidak,

- melihat komentar/review makalah dari reviewer, menetukan reviewer makalah dan mengkonfirmasi bukti pembayaran.

2. Reviewer

Reviewer adalah pengguna yang mempunyai hak tertentu dalam mengakses sistem ini. Hal-hal yang dapat dilakukan oleh reviewer yaitu:

- memanajemen akun reviewer itu sendiri,

- me-review makalah.

3. Peserta Pemakalah/Nonpemakalah

Pengguna sistem yang mendaftar sebagai peserta pada bagian login yang terletak di halaman front-end. Proses login berfungsi agar peserta dapat:

- mengunggah makalah (pemakalah),

- memanajemen akun peserta,

- mengetahui makalah diterima atau tidak (pemakalah),

- melihat informasi pembayaran biaya pelaksanaan konferensi yang sudah ditentukan,

- melihat histori makalah dan pembayaran.

4. Umum 
Semua pengguna yang membuka sistem ini, tetapi hanya memiliki hak untuk mendapatkan informasi terbatas yang disediakan oleh sistem ini di halaman front-end.

\section{Perancangan Arsitektur Sistem}

Perancangan arsitektur sistem yang akan dibangun adalah membuat aplikasi berbasis website yang dapat diakses dengan jaringan internet. Berikut perancangan arsitektur sistem pada Gambar 1 arsitektur sistem.

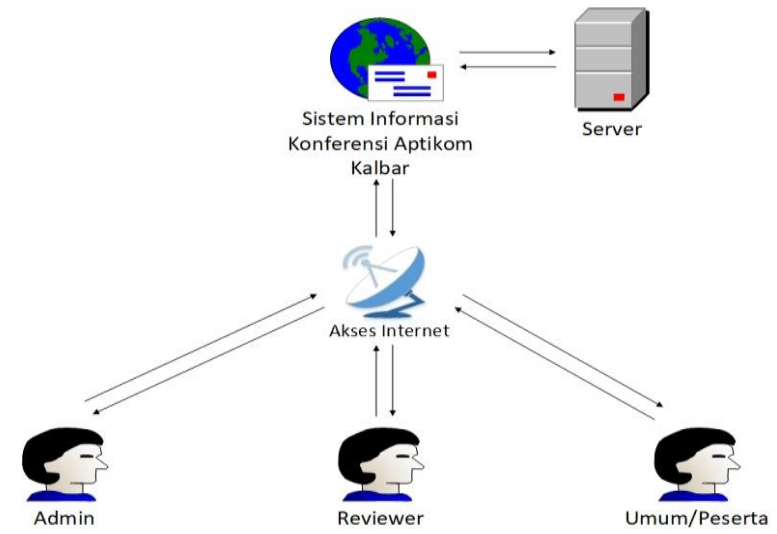

Gambar 1 Arsitektur Sistem

Proses yang terjadi adalah sebagai berikut.

1. Admin bertugas melakukan manajemen data seperti melakukan proses tambah, ubah, dan hapus dengan terlebih dahulu mengakses website Sistem Informasi Konferensi Aptikom Kalbar.

2. Reviewer dapat mengakses website Sistem Informasi konferensi Aptikom Kalbar dengan didaftarkan terlebih dahulu oleh admin. Reviewer dapat mengunduh makalah dan memberikan review kepada makalah yang telah dipilihkan oleh admin.

3. Pengguna umum dapat mengakses sistem dengan koneksi internet untuk mendapatkan informasi terbatas tentang seminar dan mendaftar sebagai peserta. Untuk peserta, dapat diubah statusnya sebagai pemakalah atau non pemakalah dengan mengakses website Sistem Informasi Konferensi Aptikom Kalbar.

D. Diagram Konteks

Diagram konteks adalah diagram yang terdiri dari suatu proses dan menggambarkan ruang linkup suatu sistem. Diagram konteks dapat dilihat pada Gambar 2.

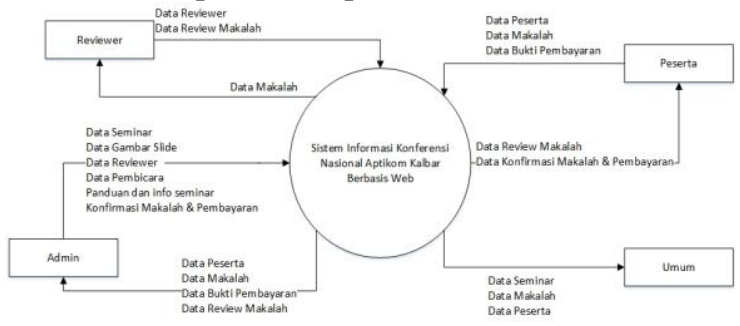

Gambar 2 Diagram Konteks

\section{E. Diagram Overview}

Diagram overview adalah diagram yang menjelaskan urutan-urutan proses dari diagram konteks. Diagram overview dapat dilihat pada Gambar 3.

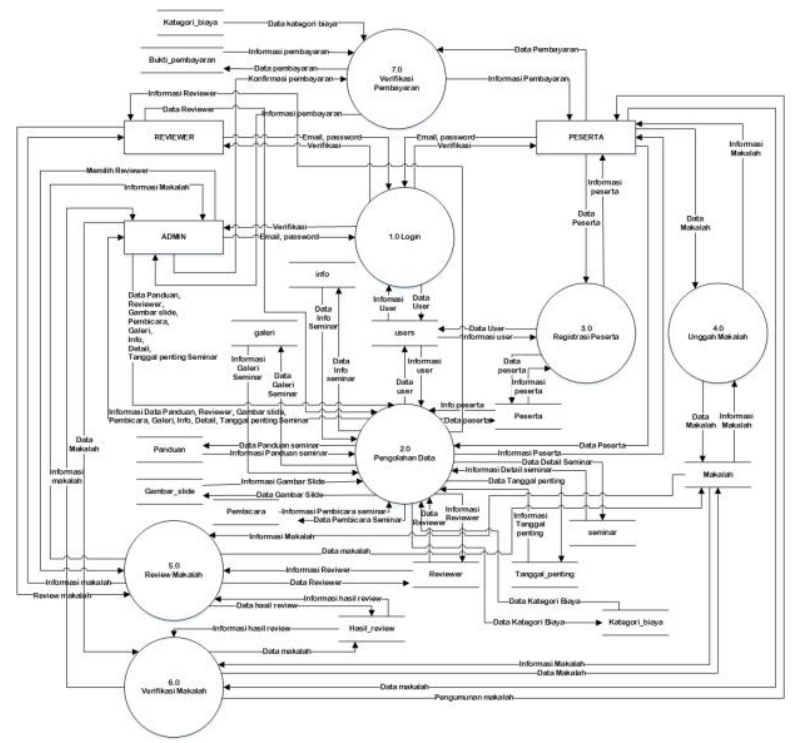

Gambar 3 Diagram Overview

\section{F. Entity Relationship Diagram (ERD)}

ERD merupakan sebuah model yang menggambarkan hubungan antar entitas yang ada dalam sistem. [9]

Berikut tampilan ERD yang telah dirancang.

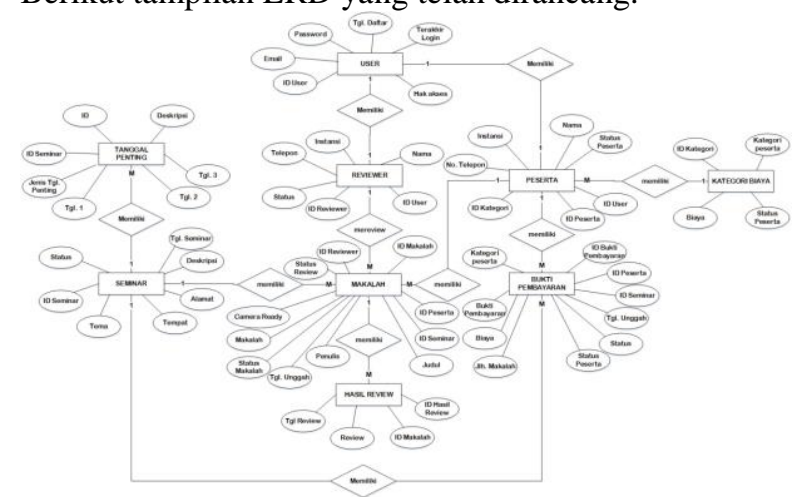

Gambar 4 Entity Relationship Diagram

\section{G. Rancangan Pengujian Sistem}

Pengujian sistem yang digunakan adalah pengujian dengan metode Black Box dengan teknik Robustness testing. Pengujian dilakukan dengan memasukan contoh data pada setiap proses dan melihat hasil eksekusinya. Tujuan dari pengujian ini adalah membuktikan bahwa tidak ada kesalahan jika masukan valid. Hasil pengujian black box akan dirangkum dalam sebuah tabel seperti pada Tabel 1 berikut.

Tabel 1 Perancangan Pengujian Black Box

\begin{tabular}{|c|c|c|c|c|}
\hline Input & Contoh Data & $\begin{array}{c}\text { Hasil yang } \\
\text { Diharapkan }\end{array}$ & Hasil & Keterangan \\
\hline
\end{tabular}




\begin{tabular}{|c|c|c|c|c|c|}
\hline Input & \multicolumn{2}{|c|}{ Contoh Data } & $\begin{array}{l}\text { Hasil yang } \\
\text { Diharapkan }\end{array}$ & Hasil & Keterangan \\
\hline \multirow[t]{3}{*}{$\begin{array}{l}\text { Input } \\
\text { data } \\
\text { kosong }\end{array}$} & $\begin{array}{l}\text { Nama } \\
\text { kolom } \\
\text { data } 1\end{array}$ & $\begin{array}{l}\text { Isi } \\
\text { kolom } \\
\text { data 1 }\end{array}$ & \multirow{3}{*}{$\begin{array}{l}\text { Sistem tidak } \\
\text { akan } \\
\text { menyimpan } \\
\text { data dan akan } \\
\text { menampilkan } \\
\text { pesan } \\
\text { kesalahan }\end{array}$} & \multirow{3}{*}{$\begin{array}{l}\text { Sesuai } \\
\text { atau } \\
\text { Tidak } \\
\text { sesuai }\end{array}$} & \\
\hline & $\begin{array}{l}\text { Nama } \\
\text { kolom } \\
\text { data } 2\end{array}$ & $\begin{array}{l}\text { Isi } \\
\text { kolom } \\
\text { data } 2\end{array}$ & & & \\
\hline & $\begin{array}{l}\text { Nama } \\
\text { kolom } \\
\text { data } 3\end{array}$ & $\begin{array}{l}\text { Isi } \\
\text { kolom } \\
\text { data } 3\end{array}$ & & & \\
\hline \multirow[t]{3}{*}{$\begin{array}{l}\text { Input } \\
\text { data } \\
\text { salah }\end{array}$} & $\begin{array}{l}\text { Nama } \\
\text { kolom } \\
\text { data } 1\end{array}$ & $\begin{array}{l}\text { Isi } \\
\text { kolom } \\
\text { data 1 }\end{array}$ & \multirow{3}{*}{$\begin{array}{l}\text { Sistem tidak } \\
\text { akan } \\
\text { menyimpan } \\
\text { data dan akan } \\
\text { menampilkan } \\
\text { pesan } \\
\text { kesalahan }\end{array}$} & \multirow{3}{*}{$\begin{array}{l}\text { Sesuai } \\
\text { atau } \\
\text { Tidak } \\
\text { sesuai }\end{array}$} & \\
\hline & $\begin{array}{l}\text { Nama } \\
\text { kolom } \\
\text { data } 2\end{array}$ & $\begin{array}{l}\text { Isi } \\
\text { kolom } \\
\text { data } 2\end{array}$ & & & \\
\hline & $\begin{array}{l}\text { Nama } \\
\text { kolom } \\
\text { data } 3\end{array}$ & $\begin{array}{l}\text { Isi } \\
\text { kolom } \\
\text { data } 3\end{array}$ & & & \\
\hline \multirow{3}{*}{$\begin{array}{l}\text { Input } \\
\text { data } \\
\text { sudah } \\
\text { ada }\end{array}$} & $\begin{array}{l}\text { Nama } \\
\text { kolom } \\
\text { data } 1\end{array}$ & $\begin{array}{l}\text { Isi } \\
\text { kolom } \\
\text { data 1 }\end{array}$ & \multirow{3}{*}{$\begin{array}{l}\text { Sistem tidak } \\
\text { akan } \\
\text { menyimpan } \\
\text { data dan akan } \\
\text { menampilkan } \\
\text { pesan } \\
\text { kesalahan }\end{array}$} & \multirow{3}{*}{$\begin{array}{l}\text { Sesuai } \\
\text { atau } \\
\text { Tidak } \\
\text { sesuai }\end{array}$} & \\
\hline & $\begin{array}{l}\text { Nama } \\
\text { kolom } \\
\text { data } 2\end{array}$ & $\begin{array}{l}\text { Isi } \\
\text { kolom } \\
\text { data } 2\end{array}$ & & & \\
\hline & $\begin{array}{l}\text { Nama } \\
\text { kolom } \\
\text { data } 3\end{array}$ & $\begin{array}{l}\text { Isi } \\
\text { kolom } \\
\text { data } 3\end{array}$ & & & \\
\hline \multirow[t]{3}{*}{$\begin{array}{l}\text { Input } \\
\text { data } \\
\text { benar }\end{array}$} & $\begin{array}{l}\text { Nama } \\
\text { kolom } \\
\text { data } 1\end{array}$ & $\begin{array}{l}\text { Isi } \\
\text { kolom } \\
\text { data 1 }\end{array}$ & \multirow{3}{*}{$\begin{array}{l}\text { Sistem akan } \\
\text { menyimpan } \\
\text { data dan data } \\
\text { ditampilkan } \\
\text { di tabel data }\end{array}$} & \multirow{3}{*}{$\begin{array}{l}\text { Sesuai } \\
\text { atau } \\
\text { Tidak } \\
\text { sesuai }\end{array}$} & \\
\hline & $\begin{array}{l}\text { Nama } \\
\text { kolom } \\
\text { data } 2\end{array}$ & $\begin{array}{l}\text { Isi } \\
\text { kolom } \\
\text { data } 2\end{array}$ & & & \\
\hline & $\begin{array}{l}\text { Nama } \\
\text { kolom } \\
\text { data } 3\end{array}$ & $\begin{array}{l}\text { Isi } \\
\text { kolom } \\
\text { data } 3\end{array}$ & & & \\
\hline
\end{tabular}

Keterangan Tabel 1 sebagai berikut.

1. Input : berisi jenis masukan yang digunakan sebagai bahan pengujian.

2. Contoh Data : berisi contoh data yang dimasukan dalam pengujian pada sistem.

3. Hasil yang diharapkan : merupakan hasil keluaran yang diharapkan jika memasukan contoh data.

4. Hasil eksekusi : merupakan hasil dari pengujian yang telah dilakukan dengan memasukan data pada kolom contoh data. Berupa status sesuai atau tidaknya proses input data dengan hasil yang diharapkan.

5. Keterangan : merupakan penjelasan dari hasil eksekusi pengujian, berupa pesan kesalahan atau respon balik dari sistem.

\section{IMPLEMENTASI DAN HASIL PENGUJIAN}

Pada Bab ini akan dilakukan implementasi dan hasil pengujian terhadap aplikasi. Tahapan ini dilakukan setelah perancangan sistem selesai dan selanjutnya akan diimplementasikan kemudian dilakukan pengujian terhadap aplikasi. Implementasi dan hasil pengujian yang dilakukan untuk mengetahui aplikasi tersebut dapat berjalan sesuai dengan tujuannya atau tidak.

\section{A. Implementasi}

Berikut beberapa fitur dari masing-masing pengguna yang terdapat pada aplikasi yang telah dibuat.

\section{Halaman Utama Tanpa Login}

Halaman utama tanpa login menampilkan konten-konten yang dapat dilihat pengunjung. Jika scoll ke bawah akan menampilkan tema seminar, tanggal penting, biaya, pembicara, info, dan galeri yang juga dapat di akses dengan memilih menu yang tersedia. Pada halaman ini juga terdapat menu pendaftaran yang digunakan untuk proses pendaftaran sebagai peserta konferensi.

\section{Halaman Admin}

Halaman admin adalah halaman awal yang muncul setelah admin berhasil login. Halaman ini berisi data yang dapat dikelola oleh admin. Pada halaman ini admin dapat mengelola data peserta, data reviewer, data makalah, data seminar, dan juga konten yang akan ditampilkan di halaman tanpa login.

\section{Halaman Peserta}

Halaman peserta merupakan halaman yang digunakan oleh peserta untuk mengolah data peserta. Halaman peserta memiliki halaman awal yang menampilkan infomasi singkat tata cara pembayaran pendaftaran, menu pengaturan akun, menu unggah makalah bagi peserta yang mendaftar sebagai pemakalah, menu verifikasi peserta, serta menu histori dengan submenu makalah dan pembayaran.

\section{Halaman Reviewer}

Halaman ini merupakan halaman yang digunakan oleh reviewer untuk me-review makalah. Halaman ini berisi daftar makalah yang akan dan telah di review oleh reviewer.

\section{Halaman Pendaftaran Peserta}

Halaman pendaftaran peserta merupakan halaman yang digunakan peserta untuk mendaftar sebagai peserta seminar dan mendapatkan hak akses aplikasi. Peserta dapat memilih kategori peserta yaitu pemakalah atau non pemakalah.

\section{Halaman Login}

Halaman login merupakan halaman yang digunakan oleh admin, reviewer, dan peserta untuk mengaskes aplikasi. Untuk login aplikasi, admin, reviewer, dan peserta harus memasukan email dan password. Peserta harus mendaftar terlebih dahulu dihalaman registrasi peserta, sedangkan reviewer ditambahkan langsung oleh admin.

\section{B. Pengujian Black Box}

Berikut ini adalah hasil dari pengujian black box dengan teknik Robustness testing yang telah dilakukan setelah melakukan serangkaian percobaan menunjukan beberapa hasil pengujian sebagai berikut.

\section{Pengujian Pendaftaran Akun}

Hasil pengujian ini, pendaftaran tidak akan berhasil jika dalam kondisi data kosong, data email salah, dan data email sudah ada sehingga sistem akan menampilkan pesan kesalahan. Pendaftaran akun akan berhasil jika input data benar dengan email baru yang belum terdaftar sebelumnya sehingga data yang dimasukan akan disimpan dan peserta akan menuju ke halaman peserta. 


\section{Pengujian Unggah Makalah}

Hasil pengujian ini, unggah makalah tidak akan berhasil jika dalam kondisi data kosong dan format data makalah bukan .pdf sehingga sistem akan menampilkan pesan kesalahan. Unggah makalah akan berhasil jika input data benar dengan format makalah .pdf sehingga data yang dimasukan akan disimpan dan data makalah akan ditampilkan pada daftar makalah yang telah diunggah.

\section{Pengujian Penambahan Call for Paper}

Hasil pengujian ini, penambahan call for paper tidak akan berhasil jika dalam kondisi data kosong dan data tanggal salah sehingga sistem akan menampilkan pesan kesalahan. Penambahan call for paper akan berhasil jika input data benar sehingga data yang dimasukan akan disimpan dan data call for paper akan ditampilkan pada daftar call for paper.

4. Pengujian Tanggal Penting

Hasil pengujian ini, perubahan tanggal penting tidak akan berhasil jika dalam kondisi data perubahan tanggal penting di isi dengan data tanggal yang sama atau tanggal yang sudah lewat sehingga akan menampilkan pesan kesalahan. Perubahan tanggal penting tetap akan berhasil walaupun ada beberapa kolom yang kosong asalkan input data benar sehingga data yang dimasukan akan disimpan.

\section{Pengujian Penambahan Reviewer}

Hasil pengujian ini, penambahan tidak akan berhasil jika dalam kondisi data kosong, data email salah, dan data email sudah ada sehingga sistem akan menampilkan pesan kesalahan. Penambahan reviewer akan berhasil jika input data benar dengan email baru yang belum terdaftar sebelumnya sehingga data yang dimasukan akan disimpan.

\section{Pengujian Tambah Gambar Slide}

Hasil pengujian ini, tambah gambar slide tidak akan berhasil jika dalam kondisi data kosong dan data gambar salah sehingga sistem akan menampilkan pesan kesalahan. Tambah gambar slide akan berhasil jika input data benar sehingga data yang dimasukan akan disimpan.

\section{Pengujian Penambahan Pembicara}

Hasil pengujian ini, penambahan pembicara tidak akan berhasil jika dalam kondisi data kosong data gambar salah sehingga sistem akan menampilkan pesan kesalahan. Penambahan pembicara akan berhasil jika input data benar sehingga data yang dimasukan akan disimpan.

\section{Pengujian Penambahan Kategori Biaya}

Hasil pengujian ini, penambahan kategori biaya tidak akan berhasil jika dalam kondisi data kosong dan data biaya bukan angka sehingga sistem akan menampilkan pesan kesalahan. Penambahan kategori biaya akan berhasil jika input data benar sehingga data yang dimasukan akan disimpan.

9. Pengujian Review Makalah

Hasil pengujian ini, review makalah tidak akan berhasil jika dalam kondisi data kosong sehingga akan menampilkan pesan kesalahan. Review makalah akan berhasil jika dalam kondisi kolom status sudah terisi tetapi kolom catatan kosong atau input data benar dengan kolom status dan kolom catatan sudah terisi sehingga data yang dimasukan akan disimpan.

\section{KESIMPULAN DAN SARAN}

Berdasarkan hasil penelitian dan pembahasan mengenai Rancang Bangun Sistem Informasi Konferensi Nasional Aptikom Provinsi Kalimantan Barat Berbasis Web, maka dapat disimpulkan sebagai berikut.

1. Hasil perancangan dan pembuatan sistem sudah dilakukan dengan baik mulai dari proses penambahan call for paper, pendaftaran peserta, unggah makalah, review makalah hingga pembayaran melalui sistem informasi konferensi nasional Aptikom Kalbar berbasi web.

2. Hasil pengujian sistem didapat melalui pengujian black box. Berdasarkan pengujian black box, sistem telah berjalan sesuai fungsinya dan dapat menangani semua proses sesuai dengan apa yang diharapkan.

Adapun hal-hal yang menjadi saran sebagai bahan pertimbangan untuk pengembangan sistem informasi yang telah dibuat agar menjadi lebih baik adalah sebagai berikut.

1. Perlu adanya penambahan fitur-fitur yang lebih lengkap seperti pencetakan kartu peserta, pengecekan kartu peserta dengan sistem barcode, dan konfirmasi pembayaran secara otomatis.

2. Sistem ini dapat dipadukan dengan sistem informasi yang ada dilingkungan Aptikom seperti website Aptikom Kalbar maupun Aptikom Pusat sehingga akan menghasilkan satu kesatuan sistem informasi yang interaktif.

\section{REFERENSI}

[1] Aptikom, "Asosiasi Pendidikan Tinggi Informatika dan Komputer Provinsi Kalimantan Barat," 2016. [Online]. Available: http://kalbar.aptikom.or.id/profil/. [Accessed: 27-Mar-2018].

[2] E. Fitri, M. Jannah, A. A. Ilham, and I. S. Areni, "Implementasi Pemrograman Content Management System Pada Rancang Bangun Platform Sistem Informasi Konferensi Berbasis Web," Tugas Akhir Tek. Inform. 2014 IMPLEMENTASI, pp. 1-8, 2014.

[3] KBBI, "Kamus Besar Bahasa Indonesia," 2016. [Online]. Available: https://kbbi.kemdikbud.go.id/Cari/Index. [Accessed: 27-Mar-2018]. A. Wibowo and B. Susanto, "Pengembangan Sistem Informasi Website KPU Daerah Istimewa Yogyakarta," J. Tek. Inform. dan Sist. Inf., vol. 2, pp. 231-243, 2016.

[5] W. P. Danu, "Teori Dasar Sistem Informasi Manajemen (SIM)," Teor. Dasar Sist. Inf. Manaj., pp. 1-33, 2012.

[6] M. Z. Lestari and N. O. Syamsiah, "Sistem Informasi Piutang pada Unit Pengelolaan Keuangan Desa ( UPKD ) Model Desa Prima Kecamatan Sungai Pinyuh Kabupaten Mempawah," JEPIN, vol. 3, no. 2, pp. 142-151, 2017.

[7] S. A. K. S. dan D. Bunyamin, "Analisis sistem informasi akuntansi data flow diagram dan flowchart pada perusahaan dagang PT.Indomarco Prismatama (Indomaret), 2016.

[8] M. H. Izzaturrahim, M. C. Saputra, and A. Pinandito, "Pengembangan Sistem Informasi Monitoring Kinerja Mesin Gilingan Berbasis Android Studi Kasus PG. Krebet Baru II, Malang," vol. 2, no. 5, pp. 2016-2024, 2018.

[9] N. Kusumarani, A. Bijaksana, and P. Negara, "Sistem Informasi Kehadiran Dosen Mengajar dengan Menggunakan Sidik Jari Pada Program Studi Teknik Informatika Universitas Tanjungpura," JUSTIN, vol. 1, no. 2, 2017. 